\title{
On the formation of AlSi10Mg single tracks and layers in Selective Laser Melting: Microstructure and Nano-mechanical properties
}

\author{
Nesma T. Aboulkhair ${ }^{\mathrm{a}, \mathrm{b}^{*}}$, Ian Maskery ${ }^{\mathrm{a}}$, Chris Tuck ${ }^{\mathrm{a}}$, Ian Ashcroft ${ }^{\mathrm{a}}$, Nicola M. Everitt ${ }^{\mathrm{b}}$ \\ ${ }^{a}$ Additive Manufacturing and 3D Printing Research Group, Faculty of Engineering, \\ University of Nottingham, Nottingham NG7 2RD, United Kingdom \\ ${ }^{\mathrm{b}}$ Bioengineering Research Group, Faculty of Engineering, University of Nottingham, \\ Nottingham NG7 2RD, United Kingdom
}

\begin{abstract}
Selective laser melting (SLM) is a relatively new manufacturing technique that can be used to process a range of materials. Aluminium alloys are potential candidates for SLM but are more difficult to process than the titanium alloys more commonly used with this technique. This is because of the former's physical properties that can result in high levels of porosity in the final parts. Although the majority of studies to date into the processing of Al alloys by SLM have considered the development of load bearing objects, in particular porosity reduction and mechanical characterization of the parts, it is also important to study the single tracks formed during the process. This paper studies the effect of changing the scan speed on the formation of fusion lines and single tracks from an $\mathrm{Al}$ alloy, as well as their overlap to form a single layer. The geometrical features of the melt pools as well as the boundaries of continuity and/or irregularities were defined and showed dependence on scan speed. Keyhole mode melting domination was observed. The scan tracks and layers were porosity-free suggesting pores to form with layer accumulation. Investigations showed that increasing the layer thickness should be avoided as it promoted defects. Energy dispersive X-ray (EDX)

*E-mail: nesma.aboulkhair@nottingham.ac.uk
\end{abstract}


mapping was implemented to compare the chemical composition distribution in the SLM material and its as-cast counterpart. A fine microstructure with homogenous distribution of the alloying elements was observed. Nanoindentation and EDX were used to establish an understanding of the hardness profile across melt pools of single tracks and their interrelation to the chemical composition. The elemental distribution yielded uniform high nano-hardness with no spatial variation across the SLM material.

Keywords: Additive manufacturing; Selective laser melting; Single tracks; Aluminium alloys; Microstructure; Nanoindentation.

\section{INTRODUCTION}

Selective laser melting (SLM) is a form of Additive Manufacturing (AM) that can be used to produce complex structures from metallic powder materials. One of the motivators for the current research in SLM is the need to manufacture the light-weight, geometrically complex structures required by the aerospace and automotive sectors. The SLM method involves building a part layer-by-layer through scanning a powder-bed with a laser beam. Yadroitsev et al. (2010) explained that a series of physical phenomena take place during processing, such as laser radiation absorption and scattering, heat transfer, phase transformation, fluid flow within the melt pool driven by the surface tension gradient, and evaporation \& emission of material. According to Hotter et al. (2012), when the laser beam irradiates a material, an energy balance between conductivity and absorptivity exists, which governs the mode of melting, either keyhole or conduction mode melting.

In SLM a 3D part is built from a series of layers. Each layer is made up of adjacent scanned tracks referred to as melt pools. In other words, the part is built through the overlap and metallurgical bonding of lines into a layer and the layers into a part. Melt pools can be 
considered as circular or cylindrical segments (Yadroitsev et al., 2010), the stability of which dictates the quality of the part on the larger scale because it affects pore formation probability. Yadroitsev et al. (2010) attributed the stability of single tracks to variation in processing parameters, such as layer thickness, scan speed, laser power, substrate material, and the properties of the powders, based on experiments on various metal alloys. They (Yadroitsev et al., 2010) observed two types of instabilities in stainless steel scan tracks dominated by scan speeds and laser power; discontinuity/droplet formation at low scan speeds when using low laser power $(25 \mathrm{~W})$ and balling at high scan speeds when using high laser power (50 W). Yadroitsev et al. (2013) demonstrated the dependence of the geometrical features of 316L stainless steel single tracks on the energy density input. Yadroitsev and Smurov (2010) showed that the selection of a layer thickness is influenced by two main factors: the powder particle size distribution and the extent of shrinkage during the process. Ciurana et al. (2013) used a tilted platform to investigate the effect of layer thickness, laser power, and scan speed, simultaneously, on CoCrMo single tracks and defined the threshold for the energy density to avoid single track defects. There are fewer studies with attention focusing on Al alloys. For example, Kempen et al. (2011) defined the major requirements to successfully produce a consolidated single track of AlSi10Mg as: (1) formation of a continuous track, (2) each layer must lightly penetrate the layer below, (3) a layer must be high enough to cumulatively build the part, and (4) a connection angle between each two layers should be ensured. The range of laser power they (Kempen et al., 2011) investigated was between $170 \mathrm{~W}$ and $200 \mathrm{~W}$. It is believed that when processing $\mathrm{Al}$ alloys with SLM, a high laser power is required for melting to substitute for the losses caused by the high reflectivity (91\% (Macleod, 2001)) and to overcome the rapid heat dissipation due to the high thermal conductivity (146 $\mathrm{W} \mathrm{m}^{-1} \mathrm{~K}^{-1}$ (ASM, 2014)). Furthermore, Yadroitsev et al. (2010) stated that the use of high laser power allows a degree of freedom for the scan speeds 
employed. However, Aboulkhair et al. (2014) used double scan strategies at high scan speeds to reduce processing defects, such as balling, and produce near fully dense $\mathrm{Al}$ parts with low laser power. So it is beneficial to investigate the possibility of producing consolidated single tracks and layers from $\mathrm{Al}$ alloys using lower laser power.

Although the majority of the work in the literature on single tracks experiments is concerned with defects and defining the zones of regularity, these experiments could have greater significance. For instance, Bartkowiak et al. (2011) conducted single track experiments to validate the feasibility of producing new blends of powder especially tailored for SLM as well as determine if there was oxidation of the surface during the processing of bulk parts. Loh et al. (2015) used information from Al6061 single track experiments to develop a simulation model that is helpful in understanding the heat transfer during SLM and further highlights the role of laser power and scan speed. Su and Yang (2012) performed a study on single layers to understand the overlap between layers, aiming at tracing porosity formation mechanisms in stainless steel 316L. A hypothesis was suggested by Dai and Gu (2014) that pores formed during processing copper matrix composites because of trapped gases in the melt pool. This is dependent on the energy density and it was suggested that they accumulate to become porosity in the bulk samples. However, this hypothesis was not verified using experiments on single tracks to show whether pores are formed in each melt pool or during the overlap of lines and/or layers through material re-melting.

Nanoindentation is a depth sensing technique that is used to test mechanical properties of materials, such as nano-hardness and Young's modulus (Fischer-Cripps, 2004). One of the characteristics of this test is that the depth of an indentation is in the micrometre range, which allows the determination of the properties of materials at a small scale. This could be beneficial in SLM due to the fine microstructure reported by Thijs et al. (2013) and distribution of phases. The application of this technique in SLM is not yet common and it has 
been mainly used to test the hardness of larger bulk parts, such as the work by Biedunkiewicz et al. (2014) on metal matrix composites processed by SLM.

This paper considers the effect of changing the scan speed on the melting and solidification of AlSi10Mg upon irradiation with a laser beam. The literature lacks information on the melting and solidification response of $\mathrm{Al}$ alloys to laser irradiation in SLM. The work in the literature mainly focussed on stainless steels except for few works, such as Kempen et al. (2011) who studied an Al alloy, whereas lightweight $\mathrm{Al}$ alloys are considered much more relevant in the field of additive manufacture. The response of the material to laser irradiation varies according to the physical properties of the target material and so results from an investigation on one material cannot be generalised for all materials. The aim is to develop an understanding of the formation of single tracks and layers as an approach to tackle difficulties in producing flaw-free 3D parts. Kempen et al. (2011) focussed on developing the process window for producing a consolidated single track, i.e. processing-focussed. We examine whether porosity is formed due to the overlap of single tracks into a layer, or during the overlap of layers to form a part. This improves upon the conventional way in which porosity is minimised in SLM parts by conducting prolonged experiments for parameters optimisation. The study is divided into two parts; the first studying fusion lines on a substrate without powder and the second studying single tracks produced from powders. The depth of penetration and width of tracks as well as the response to changing scan speeds was determined. The continuity and regularity of the scan tracks was also investigated. The difference between the microstructure and chemical composition distribution in the SLM material and conventional as-cast material was explored. Nano-hardness of both the SLM material and the as-cast material was measured and related to the microstructure to understand the microstructure-property relationship. This paper therefore contributes to available research in the field of SLM in novel aspects by filling these gaps in the literature. 


\section{EXPERIMENTAL WORK}

A Realizer GmbH SLM-50 (Germany) selective laser melting machine equipped with a $100 \mathrm{~W}$ Yttrium fibre laser (YLM-100-AC) was used in this study. The spot size of the laser beam was $20 \mu \mathrm{m}$ at the focus position. The machine processes under argon atmosphere with a 0.1\% oxygen level. An LM6 (Al-Si12\%) as-cast ingot supplied by Nigel Smith Alloys LTD (UK) was used as a substrate material. The substrate was polished and its surface was cleaned with acetone before laser scanning. AlSi10Mg powder supplied by TLS Technik GmbH (Germany) was used to create single tracks and layers. The properties of the powder are shown in Figure 1. The particle size distribution is not significantly skewed towards smaller or larger size ranges as determined using a Malvern UK Mastersizer 3000 (UK) that employs laser diffraction to measure the size of particles. Also, the morphology of the powder, imaged using a Philips XL30 scanning electron microscope (SEM) with a $20 \mathrm{kV}$ accelerating voltage using a secondary electron detector, was spherical with minor satellites. This particle size distribution and morphology allows good flowability and packing density, as was demonstrated in a flowability test conducted using the Hall flowmeter funnel according to ASTM standard B213 (2013). The flowability index and apparent density for the powder were $62 \mathrm{~s} / 50 \mathrm{~g}$ (adopting the static start to flow method) and $1.465 \mathrm{~g} / \mathrm{cm}^{3}$, respectively. The chemical composition of the powder was $86.96 \% \mathrm{Al}, 12.58 \% \mathrm{Si}$, and $0.46 \% \mathrm{Mg}$, determined by means of an energy dispersive x-ray (EDX) detector attached to the SEM. Compared to the standard, this powder had a Si content slightly higher than the expected range $(9-11 \% \mathrm{Si})$. The higher Si content makes it a eutectic alloy (Murray et al., 1984), which might affect the melting and solidification behaviour during SLM as increasing Si reduces the surface tension of the alloy, as stated by Kempen et al. (2014). 



Figure 1: (a) Particle size distribution and (b) morphology of the AlSi10Mg powder.

A series of experiments were designed and conducted to study the response of the substrate material to laser beam irradiation through fusion lines (referred to as lines hereafter), the formation of single tracks (referred to as tracks hereafter), and single layers. These experiments are explained in Table (1).

Table 1: Experimental plan and processing parameters used.

\begin{tabular}{|c|c|c|c|c|c|c|}
\hline Experiment & $\begin{array}{c}\text { With (w) or } \\
\text { without (w/o) } \\
\text { powder }\end{array}$ & $\begin{array}{c}\text { Laser } \\
\text { power }(\mathrm{W})\end{array}$ & $\begin{array}{l}\text { Speed } \\
\text { range } \\
(\mathrm{mm} / \mathrm{s})\end{array}$ & $\begin{array}{c}\text { Speed } \\
\text { increment } \\
(\mathrm{mm} / \mathrm{s})\end{array}$ & $\begin{array}{c}\text { Layer } \\
\text { thickness } \\
(\mu \mathrm{m})\end{array}$ & $\begin{array}{c}\text { Hatch } \\
\text { spacing } \\
(\mu \mathrm{m})\end{array}$ \\
\hline Fusion lines & $(\mathrm{w} / \mathrm{o})$ & & $250-1500$ & & N/A & N/A \\
\hline Scan tracks & (w) & 100 & $250-750$ & 250 & $40 \& 400$ & N/A \\
\hline Single layers & (w) & & $250-750$ & & $40 \& 400$ & 50 \\
\hline
\end{tabular}

The use of a $50 \mu \mathrm{m}$ hatch spacing for the single layers is based on a previous study by the authors (Aboulkhair et al., 2014) that showed that this hatch spacing successfully produced near fully dense SLM AlSi10Mg parts. The same reason justifies the use of a $40 \mu \mathrm{m}$ layer thickness. The motivation behind using a $400 \mu \mathrm{m}$ layer thickness is to define defects formed at large layer thicknesses. Topography of the lines and tracks was imaged using a Nikon Eclipse LV100ND microscope and SEM. Lines, tracks, and layers were cross-sectioned, polished, and imaged using optical microscopy. The geometrical parameters were measured 
from optical micrographs using the open source software ImageJ 1.46r (Abramoff et al., 2004). The microstructure of the tracks was revealed by Keller's etch (Voort, 1999). A MicroMaterials LTD Nanotest ${ }^{\mathrm{TM}}$ NTX Platform 2 nanoindenter was used to investigate the nano-hardness of the SLM material in a melt pool of a line produced using a scan speed of $500 \mathrm{~mm} / \mathrm{s}$. This speed was selected because it had previously been used to fabricate dense parts (Aboulkhair et al., 2014). Another line of indentations was conducted across melt pools in a single layer. A Berkovich tip was used for indentation. Indenter tip shape factor (diamond area function or DAF) was taken into account in the analysis as well as thermal drift pre and post indentation. Tests were performed in accordance with the ASTM standard E2546 (2007) in a load-controlled mode. The maximum indentation load was set to $7.5 \mathrm{mN}$ and the spacing between adjacent indentations was $15 \mu \mathrm{m}$. The chemical composition was determined using EDX analysis for the indented spots.

\section{RESULTS \& DISCUSSION}

\section{A. Fusion lines on a substrate material}

Lines created using various scan speeds are shown in Figure 2. The line width decreased as the scan speed increased. Irregularities and discontinuities appeared when increasing the scan speed beyond $500 \mathrm{~mm} / \mathrm{s}$. The insets in Figure 2 demonstrate the irregularities promoted by increasing the scan speed. As well as the widths of the lines, their depths also decreased with increasing the scan speed. The measurements for the geometrical parameters are represented in the plot in Figure 3 (a); showing the trend of size reduction with increasing scan speed, i.e. melt volume decreases due to less energy density delivered to the material. The melt pool was conical, see Figure 3(b), rather than hemispherical, unlike other SLM candidate materials observed by Yadroitsev et al. (2013). The depth to width aspect ratio (see Figure 3(a)) suggests keyhole mode melting rather than conduction melting as when keyhole mode melting dominates a melt pool, the depth to width ratio becomes larger than 0.5 , as reported 
by King et al. (2014).
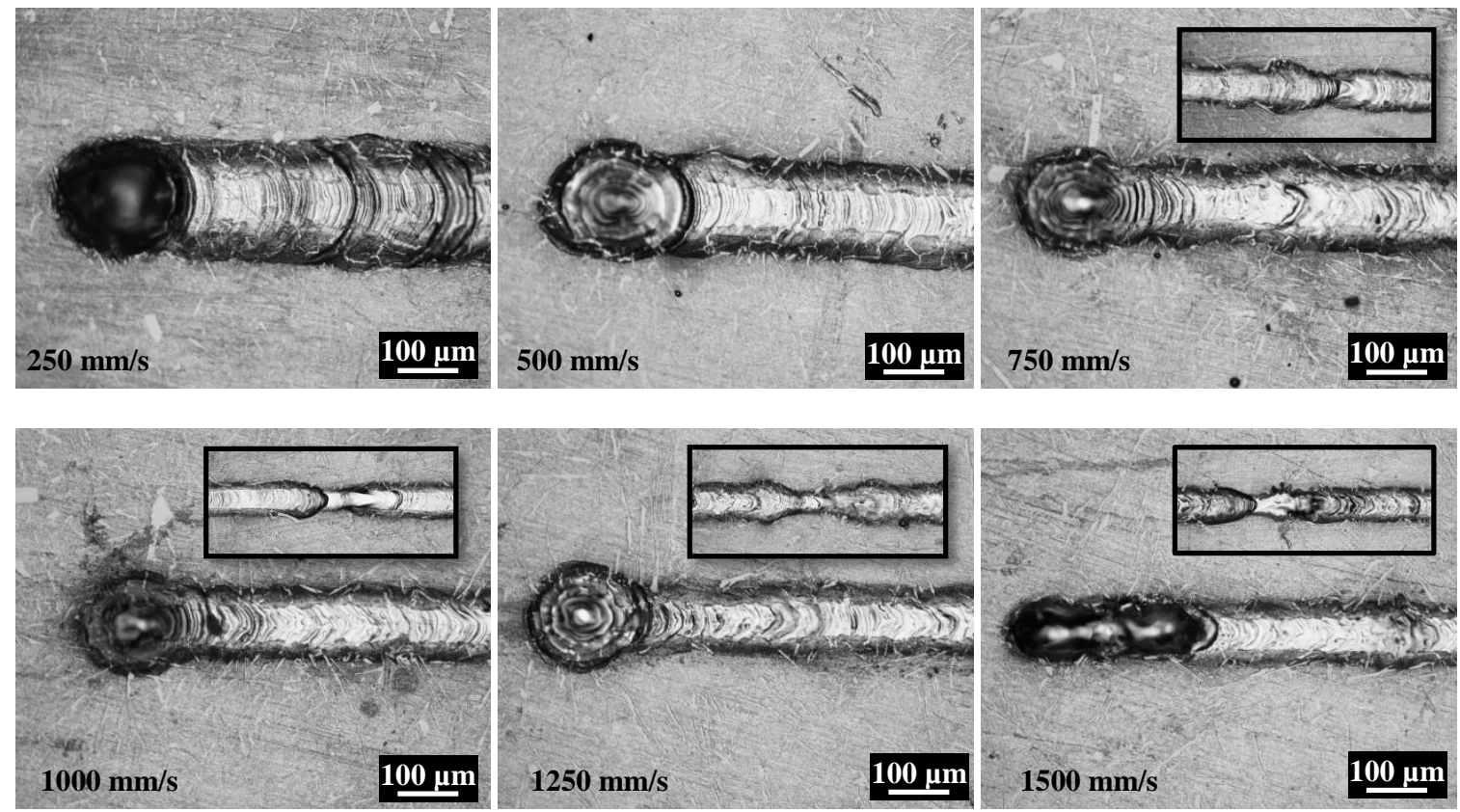

Figure 2: Thinning of fusion line with increasing scan speed. Irregularities observed at higher scan speeds are shown in the insets.

(a)


Figure 3: (a) Effect of scan speed on width and depth of penetration of the fusion lines and (b) shows an example for the cross-section of a fusion line processed at $500 \mathrm{~mm} / \mathrm{s}$.

\section{B. Single tracks from AlSi10Mg powder}

In SLM, a movable laser beam is used to melt the material. As a result of this motion, the material flows in the assigned path of the laser beam. The material solidifies in a 
characteristic chevron pattern denoting the direction of motion of the heat source, as shown in the micrographs in Figure 4. Similar to the lines, the tracks' widths decreased with increasing scan speed from $250 \mathrm{~mm} / \mathrm{s}$ to $750 \mathrm{~mm} / \mathrm{s}$, as seen in Figure 4. Also irregularities formed at $750 \mathrm{~mm} / \mathrm{s}$. In the cross-sectional views of the tracks in Figure 5, the overall height of a melt pool was divided into two sections; the height above the substrate surface and the depth of penetration into the substrate material (remelted depth). The height above the substrate increases with increasing scan speed, whereas the opposite trend is seen with the remelted depth. This implies that further increase in scan speed might lead to a reduction in the depth of penetration sufficient to result in a lack of contact between the track and the substrate material, i.e. de-cohesion of layers from one another in 3D parts. The examined processing conditions showed no evidence of balling on the surface of the scan tracks. This indicates good wettability with the substrate material which is a crucial factor affecting the bonding of a layer to the one below (wetting in SLM, as defined by Yadroitsev et al. (2013), means that molten metal has spread over the substrate or the previous layer rather than balling).


Figure 4: Single tracks formed from a $40 \mu \mathrm{m}$ thick layer of AlSi10Mg powder at different scan speeds (a) $250 \mathrm{~mm} / \mathrm{s}$, (b) $500 \mathrm{~mm} / \mathrm{s}$, and (c) $750 \mathrm{~mm} / \mathrm{s}$. Arrows denoting the scan direction. 

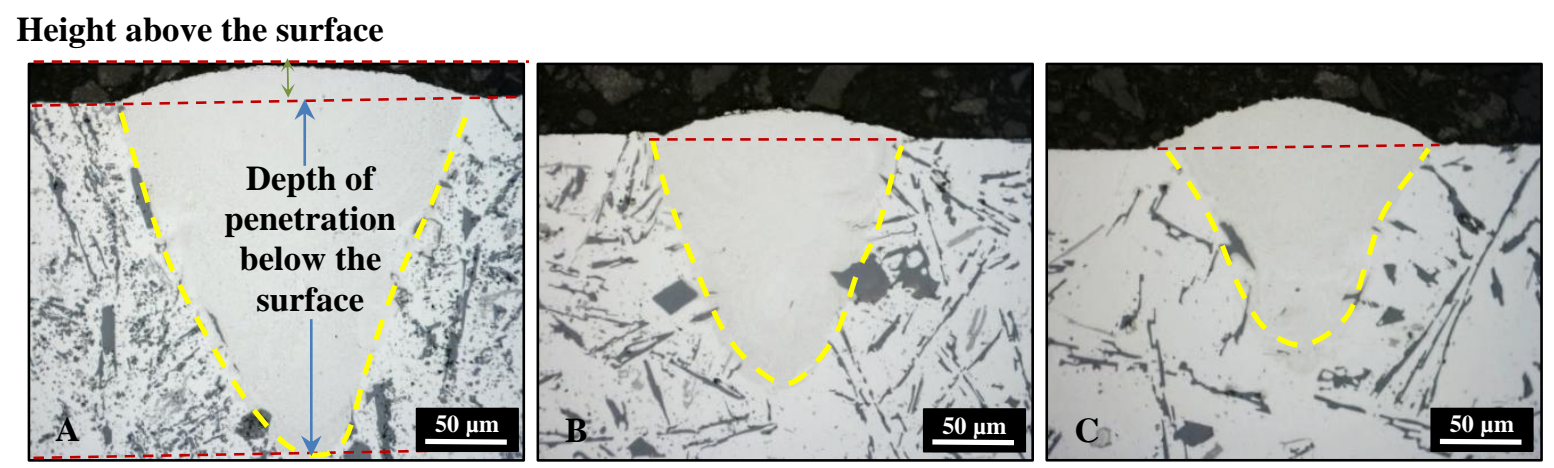

Figure 5: Cross-sectional view of single tracks (polished) formed from a $40 \mu \mathrm{m}$ thick layer of AlSi10Mg powder using different scan speeds (A) $250 \mathrm{~mm} / \mathrm{s}$, (B) $500 \mathrm{~mm} / \mathrm{s}$, and (C) $750 \mathrm{~mm} / \mathrm{s}$.

Balling is a surface defect, among others such as satellites, that is commonly reported with SLM (Aboulkhair et al., 2014). The distinction between balling and satellites is crucial and a micrograph demonstrating the difference between them can be found in Figure 6. The distinction between balling and satellites, in terms of morphology and microstructure, is a unique feature of this work and has not been published before. The term balling is used to refer to the formation of a large ball of material, with a fraction of this ball fully incorporated in the processed layer, i.e. the material was molten and then solidified in the form of a ball. This means that a ball is not a distinct entity on the surface but rather a form in which the surface solidified, as demonstrated in Figure 7. Aboulkhair et al. (2014) claimed this to be scan speed dependent and is formed due to instability. A satellite on the other hand, as defined by Yadroitsev et al. (2013), is a particle sticking to the surface of the layer having contact with the scan track. It is formed by spattering or partial re-melting of powder in the peripheral zone of the laser spot. The laser spatter phenomenon has been studied by Simonelli et al. (2015) who reported on the characteristic microstructure of the spatter material and its mechanism of formation. The presence of satellites was minimal in all the tracks in this study; however, a satellite was spotted on a track processed using $250 \mathrm{~mm} / \mathrm{s}$ and crosssectioned. This satellite, as can be seen in Figure 8, was found to have a coarse microstructure similar to the as-received powder. This supports the suggestion that satellites are formed by the spatter of particles on the single track toward the end of its solidification, 
with less energy transferred to the particle; i.e. not enough to melt it and incorporate it into the melt pool. Satellites promote the creation of pores and worsen the surface roughness, as reported by Yadroitsev et al. (2013).

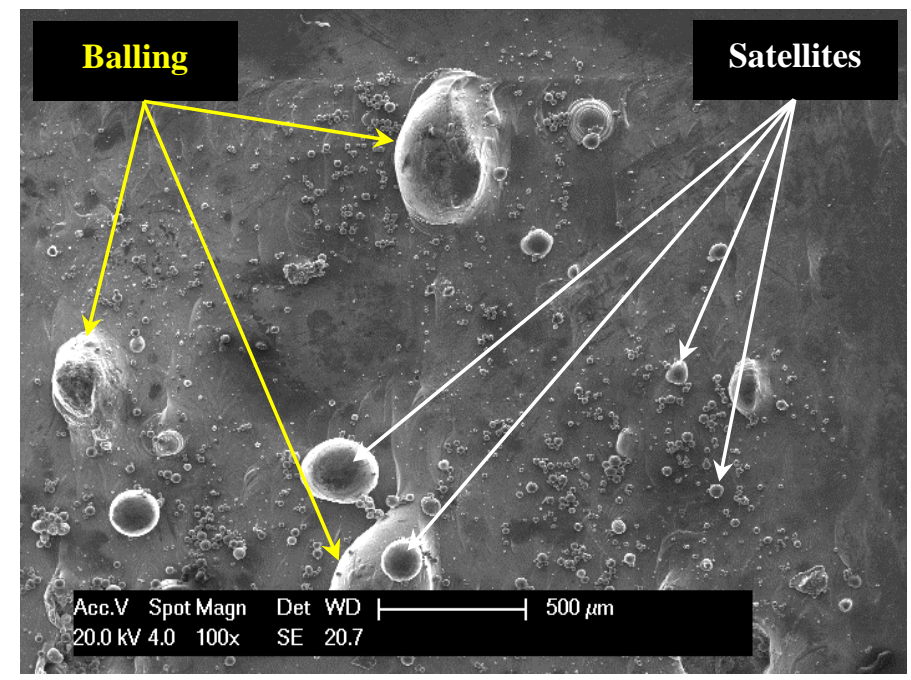

Figure 6: Excessive balling and satellites on top of the layer processed from a $400 \mu \mathrm{m}$ thick powder layer using 750 $\mathbf{m m} / \mathbf{s}$.

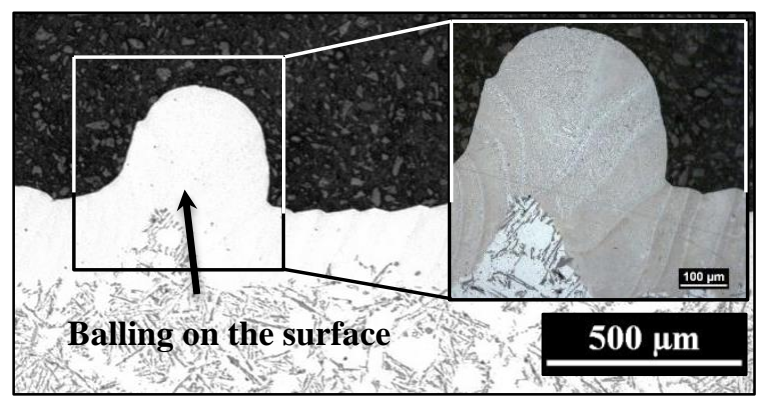

Figure 7: Cross-sectional view of a polished single layer with balling on the surface with the inset showing the balling region after etching.


Figure 8: A satellite on top of an etched single track processed using $250 \mathrm{~mm} / \mathrm{s}$ and $40 \mu \mathrm{m}$ layer thickness (a) \& (b) and cross-sectioned as-received AlSi10Mg powder (c). 
The $400 \mu \mathrm{m}$ thick powder layer yielded tracks that incorporated several defects, as can be seen in Figure 9. At all three scan speeds, the tracks incorporated excessive balling and satellites. Although $400 \mu \mathrm{m}$ is considered a thick layer, discontinuities (if defined as absolute disconnection in the scan track, i.e. zero remelted depth) were not observed at the slowest scan speed $(250 \mathrm{~mm} / \mathrm{s})$. However, discontinuities formed at $500 \mathrm{~mm} / \mathrm{s}$ and $750 \mathrm{~mm} / \mathrm{s}$ and yielded tracks which were just a series of droplets/balls. Although Yadroitsev et al. (2010) reported discontinuities and droplets forming at lower scan speeds, the results are not comparable to what is reported here due to the use of a different material, a much larger layer thickness, and higher laser power. When a ball is present, minimal energy is conducted to the substrate reducing the remelted depth drastically, which results in a lack of bonding between the track and the substrate. Cross sectional views of these tracks revealed the structure of the regions with and without balling, as shown in Figure 10, in two different characteristic regions in the track. The stability of the melt pool is controlled by good adhesion of the melt pool to the substrate, i.e. enough depth of penetration beyond the melt pool depth and into the substrate. Some of the $250 \mathrm{~mm} / \mathrm{s}$ tracks were fully consolidated into the substrate (Figure 10 (b)), however, the fraction of defects formed on the surface preclude the possibility of using large layer thicknesses. The 500 and $750 \mathrm{~mm} / \mathrm{s}$ tracks were either in the form of free circular cylinders (with a large contact angle and small remelted depth) or segmental cylinders (with a smaller contact angle and larger remelted depth). For the former shape, the remelted depth was circular whereas for the latter it was conical. Yadroitsev et al. (2010) claimed that melt pools that have the shape of segmental cylinders are more stable than free circular ones. 

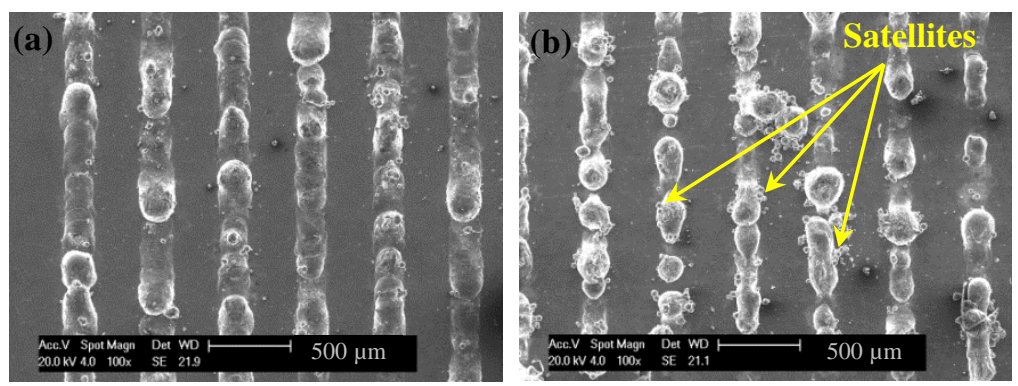

Track as a series of droplets

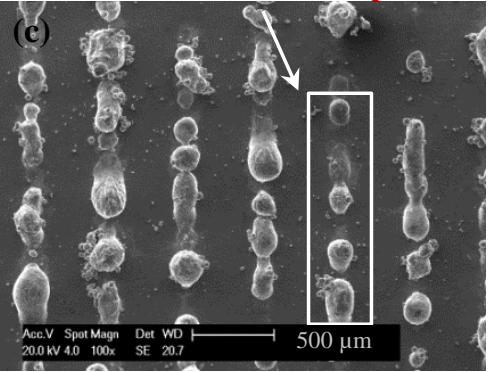

Figure 9: Single tracks formed from a $400 \mu \mathrm{m}$ thick layer of AlSi10Mg powder at different scan speeds (a) $250 \mathrm{~mm} / \mathrm{s}$,

(b) $500 \mathrm{~mm} / \mathrm{s}$, and (c) $750 \mathrm{~mm} / \mathrm{s}$.
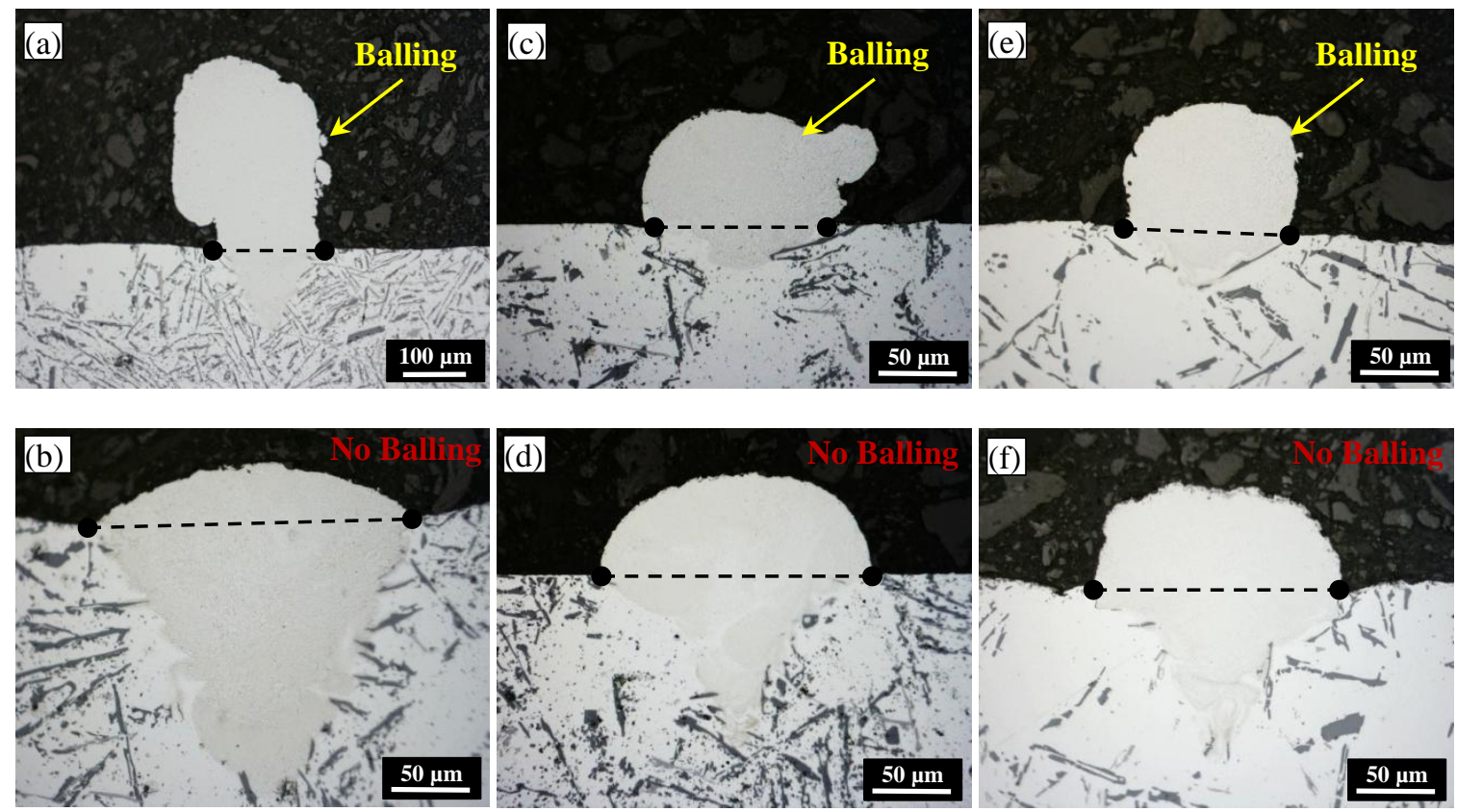

Figure 10: Single tracks with and without balling processed at $250 \mathrm{~mm} / \mathrm{s}($ a) $\&(b), 500 \mathrm{~mm} / \mathrm{s}(\mathrm{c}) \&(\mathrm{~d})$, and $750 \mathrm{~mm} / \mathrm{s}$ (e) \& (f) using a $400 \mu \mathrm{m}$ layer thickness - note the different scale bar in (a). The dashed line represents the datum for the substrate surface.

It was observed in the micrographs in Figure 5 and Figure 10 that the height of the scan track above the substrate surface was less than the height of the deposited powder layer thickness. This can be explained by a couple of reasons and these are:

1. When the powder is irradiated by the laser beam it spreads out during melting (wetting), and so the height of the scan track will decrease alongside an increase in the width. For example in the case of using $40 \mu \mathrm{m}$ powder layer thickness (Figure 5), the spot size of the laser beam is $20 \mu \mathrm{m}$ but the width of the scan track $(\sim 150 \mu \mathrm{m})$ is much larger than that due to 
wetting and heat conduction, so instead of occupying a height of $40 \mu \mathrm{m}$ and a width of $20 \mu \mathrm{m}$ the scan track is wider with less height. Likewise, in Figure 10, the height of the track is much less than $400 \mu \mathrm{m}$ and the width is larger than the $20 \mu \mathrm{m}$ spot size.

2. The powder packing density differs in bulk from after melting, i.e. there are gaps of trapped air between the powder particles that escape the melt pool after processing, meaning the volume occupied will decrease after processing.

\section{Overlap of AlSi10Mg single tracks (single layers)}

The hatch spacing of $50 \mu \mathrm{m}$ provided sufficient overlap between tracks at the examined scan speeds to yield an adequately consolidated layer, as no gaps can be seen on the surface of the layers in Figure 11. This agrees with predictions based on the widths of the corresponding tracks (Figure 5). Discoloration of the surface of the layer formed using the slowest speed $(250 \mathrm{~mm} / \mathrm{s})$ was observed and attributed to prolonged exposure times and oxidation. This discoloration decreased with increasing scan speed. Oxidation is promoted at slower speeds since the material remains molten for a longer duration increasing the likelihood of oxidation, despite the relatively low oxygen content in the processing chamber. The oxygen content originally in the substrate material and the presence of moisture on the surface of the powder contributes to increasing the possibility of oxidation. As has been illustrated by Weingarten et al. (2015), upon melting the material, moisture $\left(\mathrm{H}_{2} \mathrm{O}\right)$ on the powder surface breaks down into $\mathrm{H}_{2}$ that promotes the formation of hydrogen porosity and oxygen that combines with $\mathrm{Al}$, forming $\mathrm{Al}_{2} \mathrm{O}_{3}$.

Minimal satellites were seen on top of the $250 \mathrm{~mm} / \mathrm{s}$ layer, moreover, satellites formed as the scan speed increased. In addition, for the investigated parameters, balling on the surface did not occur for a single layer. However, this cannot guarantee no balling when processing a bulk sample with these parameters since balling could occur as further layers accumulate, as has been observed in multi-layered parts in a previous study (Aboulkhair et al., 2014) using 
the same set up and parameters. Balling was present in all layers formed from a $400 \mu \mathrm{m}$ thick powder layer, which was expected due to the poor quality of their corresponding single tracks.
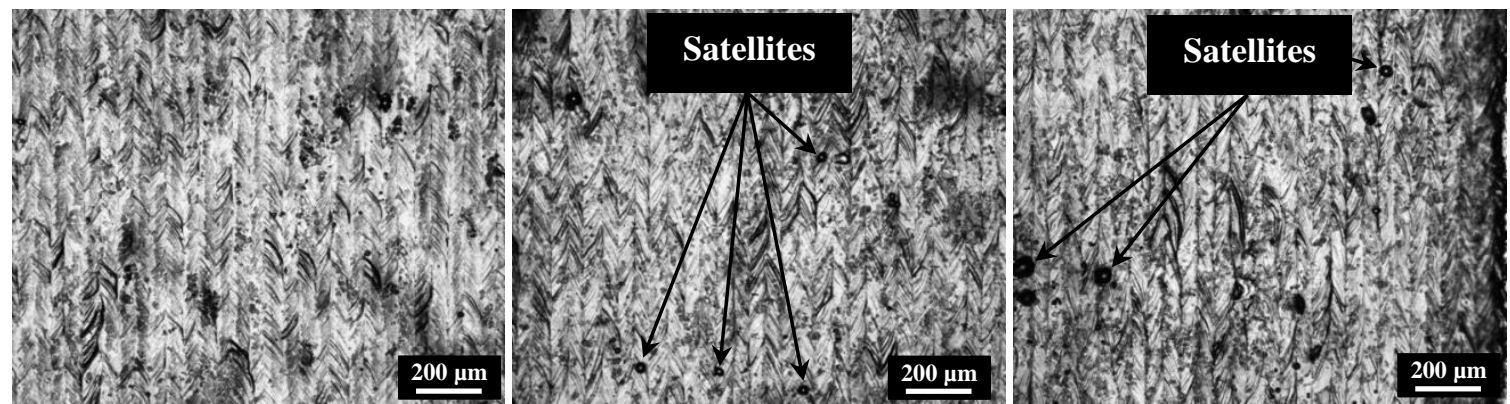

Figure 11: Topography of a $40 \mu \mathrm{m}$ thick single layer of selective laser melted AlSi10Mg using $50 \mu \mathrm{m}$ hatch spacing and (a) $250 \mathrm{~mm} / \mathrm{s}$, (b) $500 \mathrm{~mm} / \mathrm{s}$, and (c) $750 \mathrm{~mm} / \mathrm{s}$.

The cross-sectional views of the different layers were fairly similar in terms of being sufficiently overlapping. Examples for the $40 \mu \mathrm{m}$ and $400 \mu \mathrm{m}$ thick layers' cross-sections are shown in Figure 12. If we consider the substrate surface as the datum, the first few tracks were always relatively higher than the following ones, i.e. the first track is higher than the second and so on. This has been previously observed for CoCrMo single layers by Pupo et al. (2013). Yadriotsev and Smurov (2011) attributed the decrease in the height of track to substrate denudation. This feature could affect the accuracy of the parts produced by SLM. Rotating the scan pattern from one layer to another, e.g. using the alternating scan strategy (Aboulkhair et al., 2014), could be a means to remedy this surface defect, i.e. this phenomenon must be considered when designing the scan strategy to be employed during processing. This is to avoid it contributing to porosity formation or producing parts that lack dimensional accuracy. It is important to note that porosity was not observed in any of the tracks and layers formed in this study. This indicates that pores created in SLM parts from AlSi10Mg are developed with layer progression, i.e. layer-by-layer overlap, since using the same processing parameters to produce multi-layered parts yielded parts with pores, as was shown by Aboulkhair et al. (2014), that were not observed in single tracks or layers. 



Figure 12: The effect of laser denudation on the height of a layer processed using $50 \mu \mathrm{m}$ hatch spacing, $250 \mathrm{~mm} / \mathrm{s} \mathrm{scan}$ speed, and (a) $40 \mu \mathrm{m}$ layer thickness and (b) $400 \mu \mathrm{m}$ layer thickness. The dashed line represents the datum for the substrate surface.

\section{Microstructure and chemical composition mapping}

The melt pool of a $250 \mathrm{~mm} / \mathrm{s}$ track (from a $40 \mu \mathrm{m}$ thick powder layer) had fine equiaxed grains at the core and coarser grains at the boundary elongated in the direction of the thermal gradient, as can be seen in Figure 13 (a). The overlapping melt pools had the same microstructure (Figure 13 (b)). An example for the chemical composition distribution within single melt pools is shown in Figure 14. A fine microstructure with homogenous distribution of the alloying elements in the SLM material is clearly evident in the Si map. The good dispersion of the alloying elements, alongside the fine microstructure, suggests the enhanced mechanical properties required for load bearing applications. This distinctive microstructure and elemental distribution formed due to rapid solidification of the material that in turn caused structure refinement and did not allow enough time for diffusion of the alloying elements. As a result, Si particles segregated on the boundaries of the a-Al grains in the form of continuous segregations instead of forming particulates or flakes, such as those observed in the slowly cooled as-cast material. The border between two overlapping melt pools was relatively rich in $\mathrm{Al}$ compared to the rest of the melt pools, as per the micrograph in Figure 13 (b). 

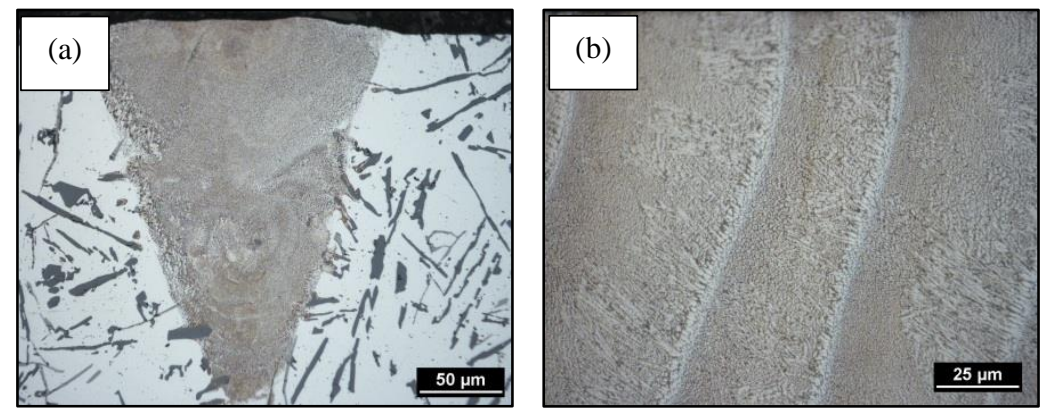

Figure 13: Microstructure of a $250 \mathrm{~mm} / \mathrm{s}$ (a) melt pool and (b) overlapping melt pools.
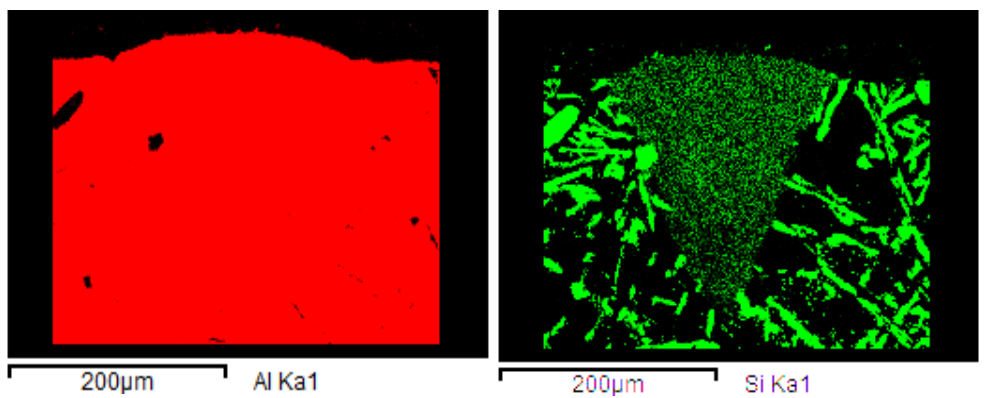

Figure 14: EDS mapping of $\mathrm{Al}, \mathrm{Si}$, and $\mathrm{Mg}$ for a track processed using $250 \mathrm{~mm} / \mathrm{s}$.

\section{E. Nanoindentation}

The array of indentations on a melt pool is shown in Figure 15 (a) incorporating both the

SLM material and the as-cast substrate. Microscopic investigation of the indentations

suggests the hardness depends on the indented phase in the case of the as-cast material with its coarse microstructure. The average hardness across the SLM material was $2.4 \pm 0.1 \mathrm{GPa}$, whereas that of the substrate (as-cast) material was $2.4 \pm 0.4 \mathrm{GPa}$. However, the latter value is inflated by the influence of localized hardness due to the coarse microstructure. The indentations coincident on the Si flakes seen in the micrographs (Figure 15 and Figure 16 (b) and (d)) showed nano-hardness values ranging between 3 and $13 \mathrm{GPa}$. Excluding these indentations, the average nano-hardness across the substrate material became $1.1 \pm 0.1 \mathrm{GPa}$. Numerical comparison of the overall nano-hardness of the SLM material compared to its ascast counterpart is not representative of the materials' behaviour. This is due to the difference in microstructure and chemical composition distribution. The fine dispersion of the alloying elements in the SLM material along with the characteristically fine microstructure results in 
an improved nano-hardness, with a homogeneous profile (Aboulkhair et al., 2015). This homogeneous profile was also observed when conducting a line of indentations across a series of overlapping melt pools in a single layer, as shown in Figure 15 (b). The variation within the profile does not show a trend with location within the melt pool, i.e. there was no registered trend between the nano-hardness at the melt pool boundary and core, as has been previously reported by the authors (Aboulkhair et al., 2015), but more of a variation with the chemical elements distribution. The evolution of nano-hardness and chemical elements distribution requires further investigation and more results are underway and will be subject to future publications.

Further investigation of the nano-indents using EDX clarified the relation between the chemical composition and the nano-hardness of the material. The chemical composition at different indentations is illustrated in Figure 16. The hardness profile across the melt pool was uniform, as was the chemical composition, as seen in Figure 16 (a). This finding further supports the suggestion that the rapid solidification of the molten material during SLM results in the formation of a fine microstructure with the alloying elements uniformly dispersed. Also, the fast cooling rate does not allow sufficient time for the alloying elements ( $\mathrm{Si}, \mathrm{Fe}$, and Mn) to diffuse and form flakes like those in the as-cast regions in Figures 16 (b) to (d). In Figure 16 (b), the difference in nano-hardness between regions rich in Si and Fe and an Alrich region is shown with the latter's nano-hardness of $0.93 \mathrm{GPa}$, whereas indenting a flake rich in $\mathrm{Si}$ and $\mathrm{Fe}$ increased the nano-hardness to 3.27 GPa. A similar effect is shown in Figure 16 (c) but the reinforcement was due to the rise in the Si content without Fe that led to increasing the hardness but to a lesser magnitude. Figure 16 (d) shows the effect of $\mathrm{Si}$ and $\mathrm{Fe}$ in addition to $\mathrm{Mn}$, where in this case, the nano-hardness increased to $9.73 \mathrm{GPa}$. 


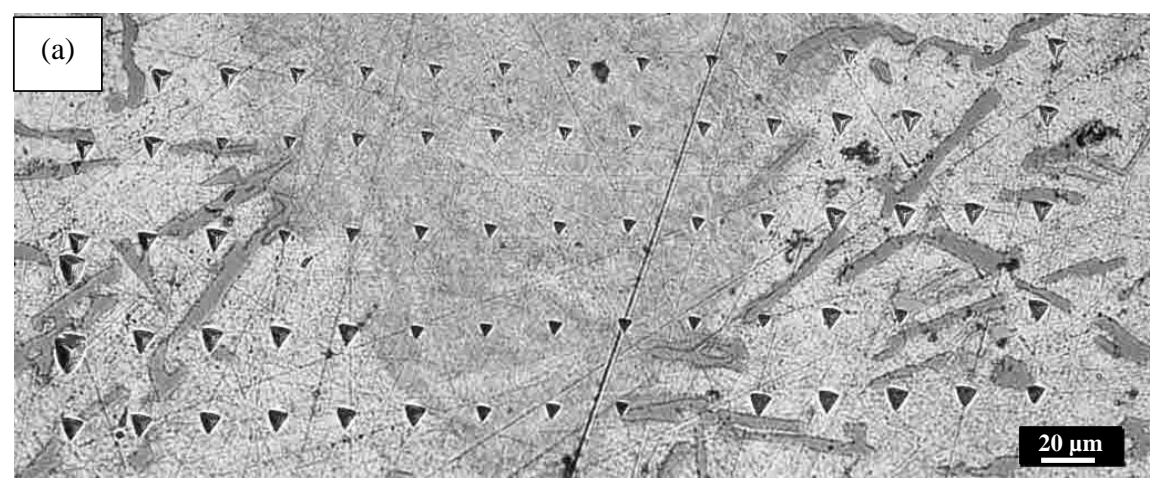

(b)
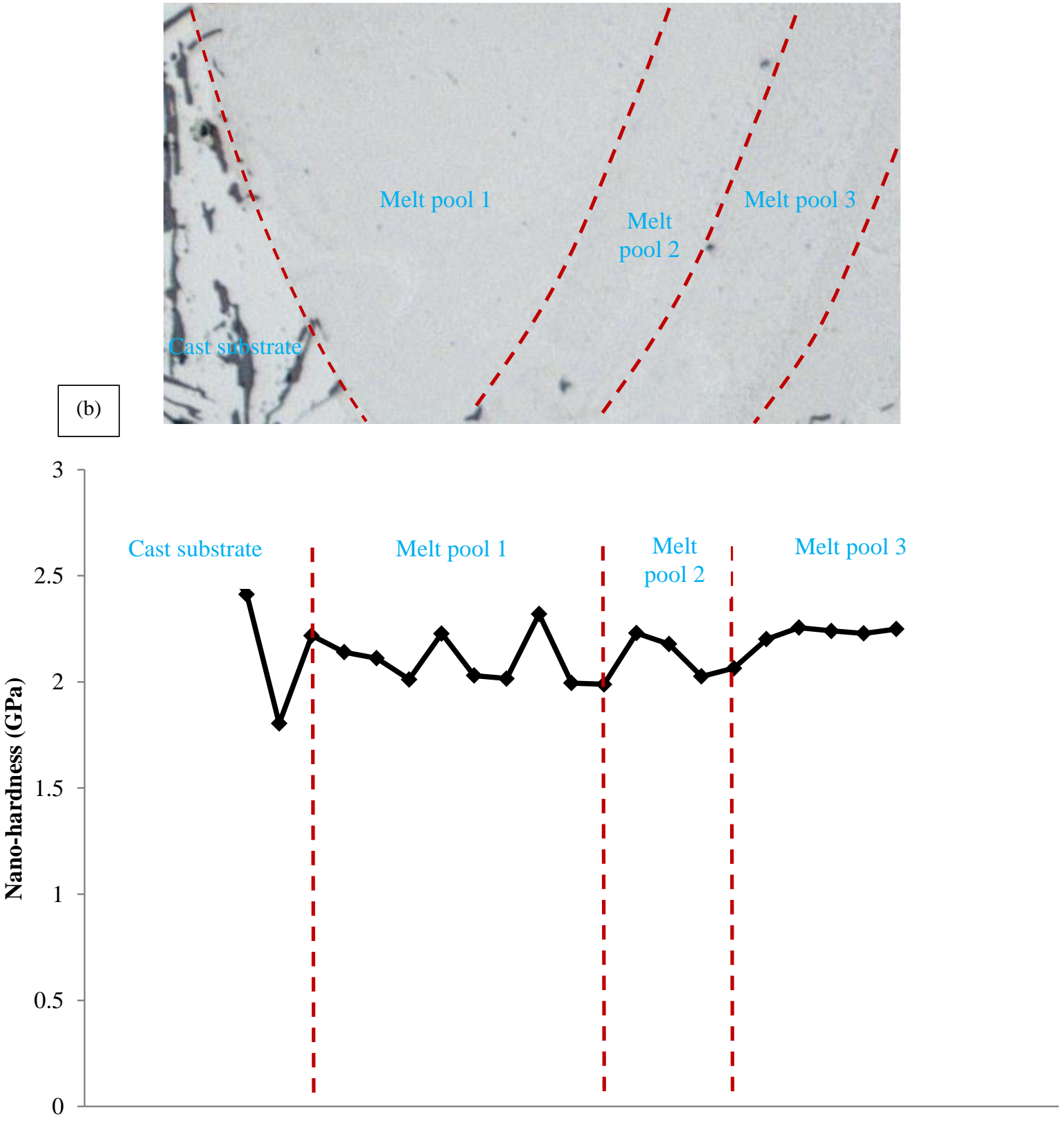

Indentation position

Figure 15: (a) Array of indentation across a melt pool and the as-cast substrate. (b) A line of indentations across overlapping melt pools in a single layer where the dashed lines represent the border between two adjacent melt pools. 

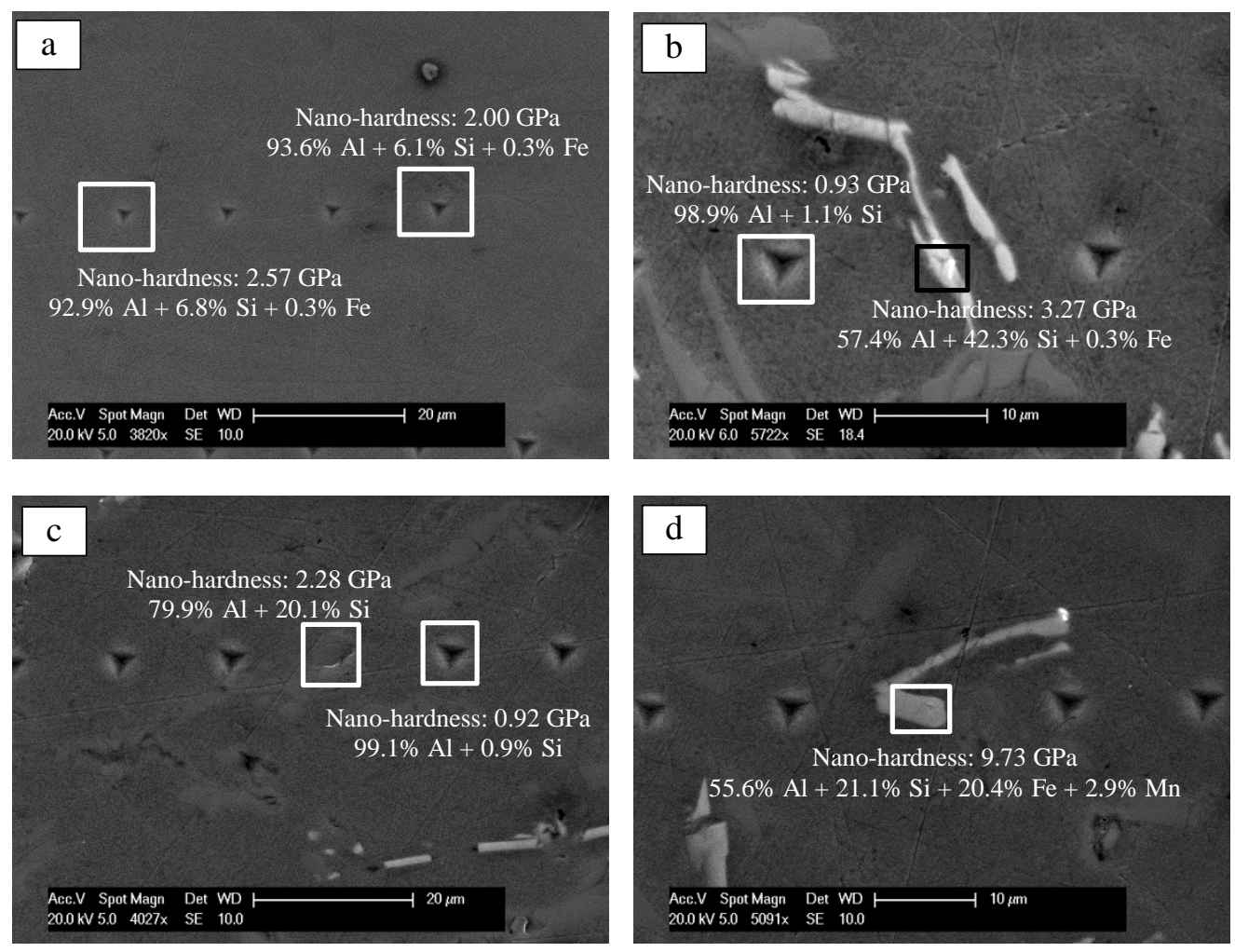

Figure 16: SEM micrographs showing nano-indents and corresponding chemical compositions across the overlapping melt pools in SLM material (a) and various regions within the substrate (b), (c), and (d).

\section{CONCLUSIONS}

We have conducted an investigation into the processability of the high strength alloy AlSi10Mg by selective laser melting. In particular, we examined the formation of single scan tracks and layers, both of which are important as they constitute the basic elements of larger consolidated SLM parts. This investigation was undertaken principally to elucidate the fundamental origin of porosity in SLM parts and to determine the mechanical response of SLM material at a level below the size of the melt pools.

The dimensions of lines and tracks, formed by SLM, decreased linearly with increasing laser scan speed. In addition, irregularities were observed at elevated scan speeds. The melt pools were conical rather than spherical (circular cylinder segment); a feature that indicated the domination of keyhole mode melting. The mode of melting adopted is dictated by the 
physical properties of the target material, AlSi10Mg, that influence the laser-material interaction. This finding opposes results published in the literature for stainless steel, for instance, where the melt pool becomes deeper with increasing the scan speed. The new insight grasped from this result is that the trend of scan track dimensions with the process parameters cannot be generalised.

There was no evidence of porosity in the cross-sections of tracks or layers, which suggests that pores form during layer accumulation in multi-layer processing. Most studies in the literature focus on the formation of single tracks and multi-layered parts with very little attention to the formation of single layers. This paper, in addition to an earlier paper by the authors (Aboulkhair et al. 2014), is the first to trace the porosity development from a single track to layers and parts. There were claims that pores form based on the energy density and remain in the multi layered parts (Dai and Gu, 2014). However, these claims were based on theoretical models and not backed up with experimental evidence on single tracks or layers. This study showed experimentally that pores do not form in single tracks or layers using a pre-defined set of parameters but they do form in multi-layered samples.

The increase in layer thickness (10X) returned tracks and layers with excessive defects, such as discontinuities, irregularities, satellites, and balling. Studying a wider range of layer thicknesses to determine its effect on the produced tracks and layers requires attention in a future study. The height of a layer decreases from one track to the following one. This phenomenon needs further attention since its continuation with layer progression could affect the quality of the final product (surface roughness/alignment and dimensional accuracy). The use of an alternating scan strategy, which accounts for this phenomenon by rotating the scan direction of each layer from the preceding one, can help avoid the height variation along a layer processed by SLM. 
The current study presents novel results in being the first to report on the distinct microstructure of single tracks and layers and its influence on the local mechanical properties determined by nanoindentation. The distribution of the elements in the SLM material is homogeneous, as has been demonstrated in the EDX maps, in contrast to the as-cast material. This is due to the fine microstructure and good dispersion of the alloying elements caused by rapid solidification. Such microstructure and chemical composition distribution is expected to enhance the load bearing properties of SLM parts. This was supported by the results from nanoindentation. The overall nano-hardness of the SLM material was higher and of a more uniform pattern compared to the as-cast material. Also sensitivity to indented phases that leads to spatial variation in nano-hardness was not apparent in SLM material owing to the homogenous blend of elements and the finer microstructure.

\section{Acknowledgment}

Nesma T. Aboulkhair gratefully acknowledges funding provided by the Dean of Engineering Scholarship for International Research Excellence, Faculty of Engineering, University of Nottingham, United Kingdom. Thanks to Mr. Mark Hardy and Mr. Tom Buss for their help in this research.

\section{REFERENCES}

Aboulkhair, N.T., Everitt, N.M., Ashcroft, I., Tuck, C., 2014. Reducing porosity in AlSi10Mg parts processed by selective laser melting, Addit. Manuf. 1-4, 77-86.

Aboulkhair, N.T., Maskery, I., Tuck, C., Ashcroft, I., Everitt, N.M., 2015. Nano-hardness and microstructure of selective laser melted AlSi10Mg scan tracks, Proceedings of SPIE, 9657, 965702-1-7.

Abramoff, M.D., Magalhaes, P.J., Ram, S.J., 2004. Image Processing with ImageJ, Biophotonics 11, 7. 
ASM, 2014. ASM Material data sheet: Aluminum 6061-T6; 6061-T651, ASM Aerospace specification metals INC, http://asm.matweb.com/search/SpecificMaterial.asp?bassnum=MA6061T6

ASTM standard B213-13, 2013, Standard test methods for flow rate of metal powder using the Hall flowmeter funnel, ASTM International, West Conshohocken, PA, 2013, Www.astm.org

ASTM standard E2546-07, 2007, Standard practice for instrumented indentation testing, ASTM International, West Conshohocken, PA, 2013, www.astm.org

Bartkowiak, K., Ullrich, S., Frick, T., Schmidt, M., 2011. New Developments of Laser Processing Aluminium Alloys via Additive Manufacturing Technique, Phys. Procedia 12, 393-401.

Biedunkiewicz, A., Figiel, P., Biedunkiewicz, W., Grzesiak, D., Krawczyk, M., GabrielPolrolniczak, U., 2014. Mechanical Properties of Metal Matrix Nanocomposites Synthesized by Selective Laser Melting Measured by Depth Sensing Indentation Technique, Local Mech. Prop. 586, 83-86.

Ciurana, J., Hernandez, L., Delgado, J., 2013. Energy density analysis on single tracks formed by selective laser melting with CoCrMo powder material, Int. J. Addit. Manuf. Technol. 68, 1103-1110.

Dai, D., Gu, D., 2014. Thermal behavior and densification mechanism during selective laser melting of copper matrix composites: Simulation and experiments, Mater. Design 55, $482-$ 491.

Fischer-Cripps, A.D., 2004. Nanoindnetation, Springer, USA.

Hotter, J., Fateri, M., Gebhardt, A., 2012. Process optimization of the SLM process with highly-reflective and thermally highly conductive materials by systematic parameter determination and accompanying simulations using the example of silver, RTejournal 9. 
Kempen, K., Thijs, L., Yasa, E., Badrossamay, M., Verheecke, W., Kruth, J-P., 2011. Process optimization and microstructural analysis for selective laser melting of AlSi10Mg, Proceedings of Annual International Solid Freeform Fabrication Symposium, Texas, USA, pp. 484-495.

Kempen, K., Thijs, L., Van Humbeeck, J., Kruth, J-P., 2015. Processing AlSi10Mg by selective laser melting: parameter optimisation and material characterisation, Mater. Sci. Tech. 31, 917-923.

King, W.E., Barth, H.D., Castillo, V.M., Gallegos, G.F., Gibbs, J.W., Hahn, D.E., Kamath, C., Rubenchik, A.M., 2014. Observation of keyhole-mode laser melting in laser powderbed fusion additive manufacturing, J. Mater. Process. Tech. 214, 2915-2925.

Loh, L-E., Chua, C-K., Yeong, W-Y., Song, J., Mapar, M., Sing, S-L., Liu, Z-H., Zhang, DQ., 2015. Numerical investigation and an effective modelling on the Selective Laser Melting (SLM) process with aluminium alloy 6061, Int. J. Heat Mass Tran. 80, 288-300. Macleod, H.A., 2001. Thin film optical filters, third ed. CRC press, United Kingdom. Murray, J.L., McAlister, A.J., 1984. The Al-Si (Aluminum-Silicon) system, Bulletin of Alloy Phase Diagrams 5, 74-84.

Pupo, Y., Delgado, J., Serenó, L., Ciurana, J., 2013. Scanning Space Analysis in Selective Laser Melting for CoCrMo Powder, Procedia Eng. 63, 370-378.

Simonelli, M., Tuck, C., Aboulkhair, N.T., Maskery, I., Ashcroft, I., Wildman, R.D., Hague, R., 2015. A Study on the Laser Spatter and the Oxidation Reactions During Selective Laser Melting of 316L Stainless Steel, Al-Si10-Mg, and Ti-6Al-4V, Metall. Mater. Trans. A, 110.

Su, X., Yang, Y., 2012. Research on track overlapping during Selective Laser Melting of powders, J. Mater. Process. Tech. 212, 2074-2079. 
Thijs, L., Kempen, K., Kruth, J-P., Van Humbeeck, J., 2013. Fine-structured aluminium products with controllable texture by selective laser melting of pre-alloyed AlSi10Mg powder, Acta Mater., 61, 1809-1819.

Voort, G.F.V., 1999. Metallography: Principles \& practice, ASM International, USA.

Weingarten, C., Buchbinder, D., Pirch, N., Meiners, W., Wissenbach, K., Poprawe, R., 2015. Formation and reduction of hydrogen porosity during selective laser melting of AlSi10Mg, J. Mater. Process. Tech. 221, 112-120.

Yadroitsev, I., Gusarov, A., Yadroitsava, I., Smurov, I., 2010. Single track formation in selective laser melting of metal powders, J. Mater. Process. Tech. 210, 1624-1631.

Yadroitsev, I., Smurov, I., 2010. Selective laser melting technology: From the single laser melted track stability to 3D parts of complex shape, Phys. Procedia 5, 551-560.

Yadroitsev, I., Smurov, I., 2011. Surface Morphology in Selective Laser Melting of Metal Powders, Phys. Procedia 12, 264-270.

Yadroitsev, I., Krakhmalev, P., Yadroitsava, I., Johansson, S., Smurov, I., 2013. Energy input effect on morphology and microstructure of selective laser melting single track from metallic powder, J. Mater. Process. Tech. 213, 606-613. 